\title{
PERANCANGAN 3D PRINTER TIPE CORE XY BERBASIS FUSED DEPOSITION MODELING (FDM) MENGGUNAKAN SOFTWARE AUTODESK INVENTOR 2015
}

\author{
Anief Awalia Nurul Amri ${ }^{1}$,Wirawan Sumbodo ${ }^{2}$ \\ ${ }^{1,2}$ Fakultas Teknik Universitas Negeri Semarang \\ Email: aniefawalia908@gmail.com
}

\begin{abstract}
The purpose of this research are to determine the mechanical strength of a 3D Printer frame design of type Core XY using Autodesk Inventor 2015 and to assess the build quality of the 3D Printers. This is an R\&D research following the Pahl \& Beitz's methods which comprises of the following stages: Task or specifications, planning and clarification, conceptual design, embodiment design, and detailed design. Data were analyzed using descriptive statistics. The results show that the mechanical strength of the $3 D$ printer frame is satisfactory and is proven by the Autodesk Inventor 2015 analysis. The printed workpiece has a tolerance of $\pm 0,5 \mathrm{~mm}$. It is concluded that the type core XY 3D Printer is ready to use for printing 3-dimensional objects.
\end{abstract}

Keywords: $3 d$ pinter, core xy, inventor

\section{ABSTRAK}

Tujuan penelitian ini adalah untuk mengetahui kekuatan struktur mekanik dari perancangan desain rangka 3D Printer tipe Core XY menggunakan software Autodesk Inventor 2015 dan mengetahui kualitas produk hasil 3D Printer yang dibuat. Penelitian ini merupakan jenis perancangan dengan metode Pahl \& Beitz dengan tahapan penjabaran tugas atau spesifikasi, perancangan konsep, perancangan wujud, dan perancangan secara terperinci. Analisis data menggunakan statistik deskriptif. Hasil analisis data menunjukkan bahwa kekuatan rangka 3D Printer cukup baik dibuktikan dengan analisis menggunakan software Autodesk inventor 2015 dan hasil benda kerja yang diproses menggunakan 3D Printer mempunyai nilai kepresisian dengan toleransi $\pm 0.5 \mathrm{~mm}$ dibuktikan dengan hasil pengukuran benda kerja dengan menggunakan alat ukur. Jadi disimpulkan bahwa 3D Printer tipe core XY yang dibuat layak digunakan untuk proses pembuatan benda 3 Dimensi.

Kata kunci: 3D Printer,Core XY, Inventor

\section{PENDAHULUAN}

Perkembangan teknologi mengalami peningkatan yang sangat pesat seiring dengan perkembangan zaman. Perkembangan teknologi ini berbanding lurus dengan berkembangnya peradaban manusia modern. Teknologi yang ada saat ini membantu manusia dalam melakukan segala aktivitas sehari-hari khususnya pada sektor industri. Sektor industri pada era disrupsi ini memasuki sektor industri 4.0 dimana industri terus mengalami perkembangan yang pesat, terutama di bidang manufaktur, desain suatu produk menjadi sangat penting mengingat begitu ketatnya pesaing dan cepatnya inovasi yang dikeluarkan oleh produsen untuk mendapatkan pasar penjualan (Sumantri, 2012).

Untuk menjaga stabilitas industri pada pasar penjualan dalam pengembangkan produknya, industri membutuhkan alat yang memiliki ketelitian tinggi dan waktu pembuatan yang cepat untuk mempermudah proses produksi seperti alat yang digunakan untuk membuat prototype, sehingga banyak industri yang mengaplikasikan mesin CNC (Computer Numerical Control) dalam proses produksinya. Mesin CNC telah berkembang secara menakjubkan karena mesin CNC dapat membuat benda kerja yang rumit sekalipun dapat dibuat secara mudah dalam jumlah banyak (Sumbodo, 2008). 
Jenis mesin yang menggunakan CNC diantaranya CNC router, lathe, plasma cutter, dan 3D printer. Fungsi dari CNC sendiri itu adalah mesin yang bekerja dengan membaca koordinat jarak suatu objek 2 dimensi atau 3 dimensi menjadi perintah G-Code dengan bantuan komputer, dimana perintah tersebut akan menggerakan motor sehingga motor dapat bergerak sesuai dengan koordinat objek tersebut. Mesin CNC merupakan mesin yang mudah diaplikasikan pada industri, akan tetapi sulit diaplikasikan pada industri kecil karena mahalnya harga mesin CNC itu sendiri dan mahalnya biaya perawatan sehingga dengan perkembangan teknologi saat ini sangat cocok untuk mengembangkan teknologi 3D Printer dalam membuat prototype atau cetakan menggunakan sistem CNC dengan harga murah, cepat, dan presisi.

3D Printer merupakan salah satu terobosan inovasi terbaru dalam dunia teknologi sesuai dengan era industri 4.0. (More, 2013) mengatakan bahwa 3D Printer adalah sebuah alat fabrikasi komputer dekstop atau manufaktur aditif yang digunakan untuk proses prototyping dimana membuat benda nyata dari desain 3D. Teknologi yang umum digunakan dalam 3D Printer adalah Selective Laser Sintering (SLS) dan Fused Deposition Modeling (FDM) (Al-Maliki, 2015).

Penggunaan 3D Printer di Indonesia mulai disoroti karena 3D printer ini mempermudah manusia dalam membuat prototype. Pada umumnya pembuatan prototype membutuhkan waktu yang lama, hal ini dikarenakan pembuatan prototype melalui beberapa tahapan dari pembuatan desain hingga finishing. Sehingga pada proses pembuatan prototype secara konvensional memerlukan banyak pekerja dan membutuhkan waktu yang lama untuk proses produksi prototype (Tseng dan Tanaka, 2000). Oleh karena itu para ilmuan berfikir untuk menemukan inovasi teknologi terbaru yang harus dikembangkaan pada saat ini yaitu 3D Printer. Saat ini teknologi rapid prototyping banyak digunakan dalam pembuatan prototype (Priyanto, 2005). 3D
Printer menggunakan teknologi rapid prototyping yaitu teknologi yang berasal dari data software desain seperti solidwork, inventor, autocad, dan lain lain menggunakan metode yang mengghasilkan suatu produk dengan cara menumpuk bahan lapisan demi lapisan. Namun saat ini 3D Printer yang ada belum dianalisis secara rinci mengenai kekuatan rangka dan keefektifitasan produk hasil dari 3D Printer itu sendiri. Keberadaan 3D Printer ini diharapkan menjadi solusi untuk mengatasi permasalahan yang dijumpai dalam dunia industri ,khususnya dalam pembuatan prototype secara konvensional. Beberapa jenis model 3D Printer diantaranya model cartesian, delta, corexy. Dari beberapa model tersebut sistem corexy adalah sistem yang banyak digunakan dalam industri untuk memposisikan area dua dimensi persegi panjang

Seiiring dengan perkembangan teknologi tersebut, 3D Printer selain dibutuhkan dalam dunia industri juga dibutuhkan dalam dunia pendidikan. 3D Printer merupakan inovasi teknologi baru di dunia pendidikan, 3D Printer ini memperlancar proses pembelajaran secara langsung (Cleplak, dkk 2014). Untuk itu 3D Printer sangat dibutuhkan salah satunya di Jurusan Teknik Mesin UNNES yang belum memiliki 3D Printer untuk membantu proses pembelajaran, praktikum, dan pembuatan prototype, sehingga Jurusan Teknik Mesin UNNES dapat lebih mengikuti perkembangan teknologi sesuai dengan perkembangan dunia industri yang saat ini mulai menggunakan 3D Printer sesuai dengan konsep link and match.

Penelitian ini dalam rangka merancang dan mengembangkan mesin rapid prototyping yaitu 3D Printer tipe Core XY berbasis fused deposition modelling dengan menggunakan software autodesk inventor 2015. Selain itu juga melakukan analisis kekuatan mekanik rangka 3D Printer dan produk hasil yang akurat sehingga dapat menggerakan motor sesuai perintah dan menghasilkan produk 3D Printer sesuai dengan desain yang diinginkan. Bagaimana kekuatan struktur mekanik dari desain rangka 3D printer tipe CoreXY 
menggunakan software Autodesk Inventor 2015 dan kualitas Produk hasil 3D Printer dari 3D Printer yang dirancang.

\section{METODE}

Berikut ini adalah beberapa bahan yang dibutuhkan dalam penelitian antara lain: Arduino Mega 2560, Driver Stepper a4988, Bipolar Stepper Motor, Motor Stepper Unipolar, Motor Stepper, Ramps 1.4, Limit Switch, Heater, Lead Screw 8mm + Nut, LCD, Akrilik, Kabel, Linear motion Bearing, Exstruder set, Heat Bed, Smooth Rod, Kopling, Pulley 2, Ekstruder MK, Alumunium, dan Triplek.

Beberapa alat yang akan digunakan dalam penelitian antara lain: Jangka sorong, Bor, Gerinda Tangan, Gunting, Solder, Obeng +, Obeng -, Mata Bor, Tang Cucut, Gergaji, Lem Tembak, Lem Alteko dan Multimeter

Metode yang digunakan pada penelitian ini merupakan metode perancangan Pahl \& Beitz. Pada penelitian ini, perancangan 3D Printer tipe core xy meliputi perancangan mekanik, elektronik,dan pemrograman mesin 3D Printer. Dimana analisis kekuatan mekanik dari rangka 3D Printer menggunakan software autodesk inventor 2015 dan analisis hasil produk 3D Printer yang dihasilkan merupakan obyek penelitian pada penelitian ini. Analisis data yang digunakan pada penelitian ini adalah statistik deskriptif.

\section{HASIL DAN PEMBAHASAN}

Desain 3D Printer yang dihasilkan merupakan hasil pengumpulan data dari literatur, survey lapangan, dan perhitungan yang telah dilakukan. Berikut ini adalah desain 3D Printer menggunakan software autodesk inventor yang dihasilkan:
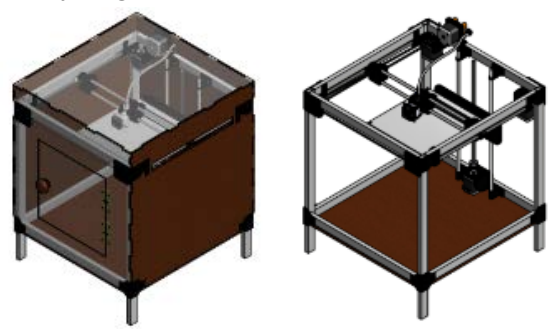

Gambar 1. Desain 3D Printer

Spesifikasi perancangan bangun 3D Printer didapatkan data sebagaisebagaimana disajikan pada Tabel 1.

Tabel 1. Spesifikasi fisik CNC bubut microkinetic

\begin{tabular}{ll}
\hline \multicolumn{1}{c}{ Spesifikasi Mesin CNC Retrofit Bubut Microkinetic } \\
\hline Printer Type & Core XY \\
Struktur Rangka 3D Printer & Aluminium \\
Dimensi Mesin & $400 \mathrm{~mm}$ x $400 \mathrm{~mm}$ x $500 \mathrm{~mm}$ \\
Dimensi Bed & $220 \mathrm{~mm}$ x $220 \mathrm{~mm}$ \\
Sistem tranmisi penggerak meja & Motor stepper nema 17 \\
Panjang leadscrew sumbu Z & $380 \mathrm{~mm}$ \\
Power Supply & 12 Volt \\
Belt type & MXL \\
Pulley type & 30 teeth \\
Smooth rod diameter & 8 mm \\
Bearing movement & Linear bearing \\
Controller & Arduino mega 2560 \\
Memory card & SD Card \\
Connections & USB \\
File print format & Stl, gcode \\
Display \& menu switch & Lcd 128x64 \\
Type moving & Pulley and timming belt mxl \\
Printing material & Pla, abs \\
Extruder max & 100 mm \\
Colling hot end & Fan with pwm controlled \\
Nozzle diameter & 0.4 mm \\
Filament diameter & 1.75 mm \\
\hline
\end{tabular}


Tabel 2. Spesifikasi penggerak sumbu CNC bubut microkinetic

\begin{tabular}{ll}
\hline \multicolumn{1}{c}{ Spesifikasi Motor Stepper Penggerak Sumbu Mesin } \\
\hline Size & NEMA 17 \\
\hline Drive System & Unipolar \\
Step angle & $1.8^{\circ}$ \\
Voltage & 12 Volt \\
Current & 0.4 Ampere/phase \\
Holding torque & 2000 g-cm \\
$\mathrm{R}$ & 30 Ohm/phase \\
\hline
\end{tabular}

Analisis kekuatan rangka 3D Printer pada penelitian ini menggunakan software autodesk inventor 2015, dimana pada software ini rangka dari 3D Printer yang sudah dirancang dianalisis kekuatannya dengan memberikan beban pada keempat bagian 3D Printer sebesar 9,32 N.

Selanjutnya adalah menentukan constraint dan pembebanan. Langkahnya adalah menentukan constraint dilakukan dengan acuan posisi dari tumpuan yang ada pada produk desain yang telah dimodelkan. Constraints dapat berupa fixed constraints, pin constraints, dan friction constraints. Sedangkan beban 9,32 N. Gambar 2 menunjukkan hasil simulasi pada beban maksimal yaitu 9,32 N.

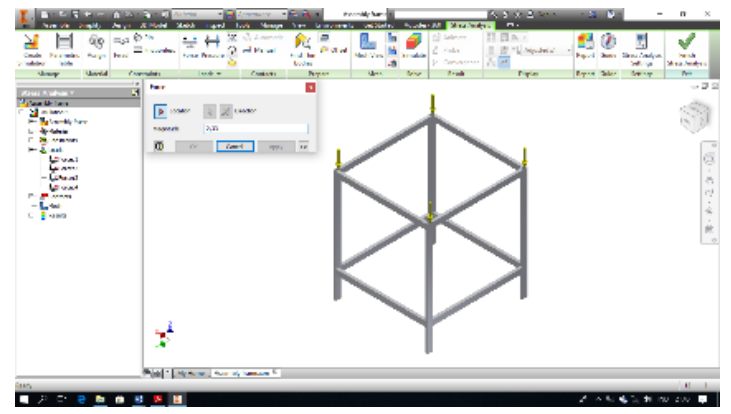

Gambar 2. Tampilan pembebanan gaya dengan beban $9,32 \mathrm{~N}$

Meshing merupakan langkah utama dalam analisis struktur menggunakan metode elemen hingga, dimana proses ini membagi benda yang akan dianalisis menjadi beberapa bagian sehingga struktur utama menjadi bagian bagian yang memiliki ukuran lebih kecil. Pada simulasi saat ini, frame dijadikan 9.649 elements dan 18.678 nodes, sebagaimana ditunjukkan pada Gambar 3.

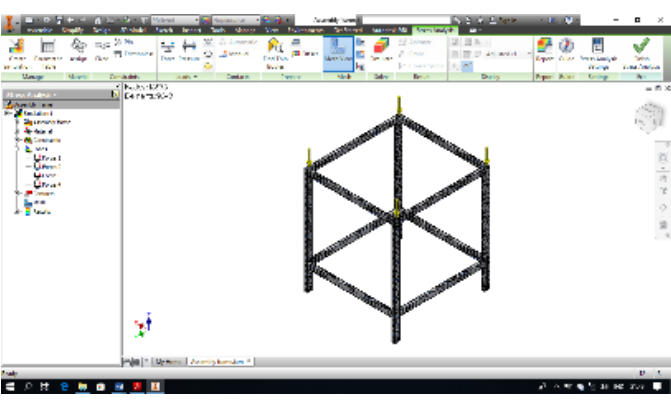

Gambar 3. Tampilan proses meshing

Langkah berikutnya adalah End Simulation. Setelah proses running, maka didapat hasil-hasil dari simulasi tersebut. Terdapat beberapa hasil yaitu berupa von misses stress, $1^{\text {st }}$ principal stress, $3^{\text {rd }}$ principal stress, displacemment, dan safety factor.

Tegangan salah satu post-proccessor adalah hasil perhitungan hubungan tegangan regangan pada model benda, regangan diperoleh dari deformation yang dialami model. Tegangan ekivalen yang digunakan metode Von-Mises. Gambar 4 merupakan ilustrasi hasil analisis equivalent stress.

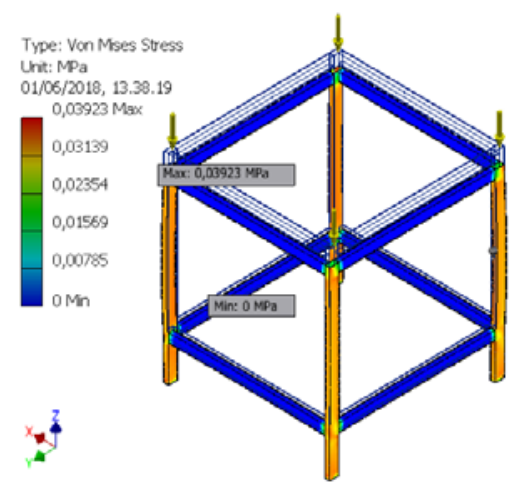

Gambar 4. Tampilan Equivalent stress dengan beban $9,32 \mathrm{~N}$

Tegangan ekivalen maksimum terjadi di bagian rangka pojok atas sebesar 0,03923 MPa, 
kemudian tegangan ekivalen minimum sebesar 0 MPa.

Hasil utama dari analisis struktur statis menggunakan metode elemen adalah deformation atau displacement. Berikut ini ilustrasi hasil analisis total deformation pada model. Hasil simulasi menunjukkan bahwa total deformation terbesar ada pada rangka bagian atas sebesar $2,458 \times 10^{-4} \mathrm{~mm}$, dan total deformation terkecil ada pada rangka bagian bawah yang dekat dengan fix Constraints / daerah tumpuan yaitu sebesar $0 \mathrm{~mm}$. Gambar 5 merupakan ilustrasi total deformation dengan kondisi undeformed shape dari model.

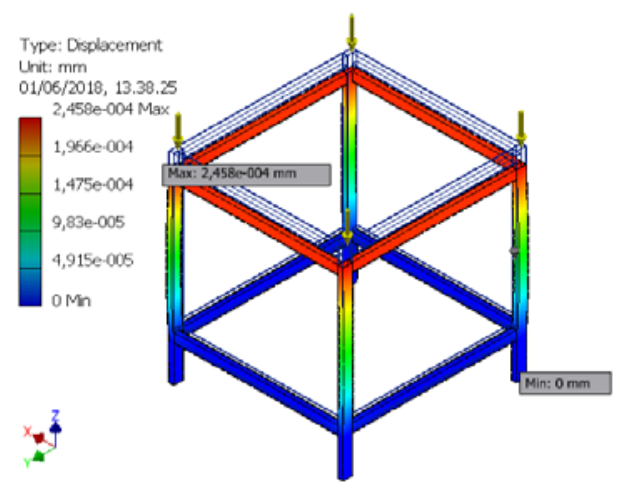

Gambar 5. Tampilan displacement

Safety factor atau angka keamanan merupakan salah satu parameter penting untuk menentukan apakah suatu konstruksi itu aman atau tidak. Safety Factor merupakan perbandingan antara tegangan ijin bahan dengan tegangan yang terjadi. Konstruksi dinyatakan aman apabila angka keamanannya di atas satu.

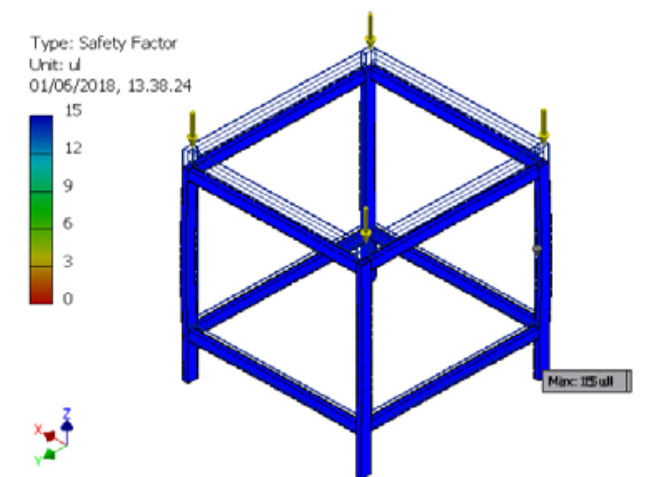

Gambar 6. Tampilan safety factor
Tabel 3. Rekapitulasi simulasi konstruksi frame

\begin{tabular}{lcc}
\hline \multicolumn{2}{c}{ Hasil Simulasi } & Beban \\
& & $\mathbf{9 , 3 2} \mathbf{~ N}$ \\
\hline \multirow{2}{*}{ Von Misses } & Maximum & $0,03923 \mathrm{MPa}$ \\
& Minimum & 0 \\
Displacement & Maximum & $2,458 \times 10^{-4} \mathrm{~mm}$ \\
& Minimum & 0 \\
Safety Factor & Maximum & 15 \\
& Minimum & 0
\end{tabular}

Gambar 6. dan Tabel 3. Menunjukkan bahwa pada pembebanan maksimum yaitu saat berat 9,32 $\mathrm{N}$ diperoleh angka keamanan tertinggi $=15$ yaitu pada bagian rangka bawah yang dekat dengan fix Constraints / daerah tumpuan, sedangkan angka keamanan terendah $=0$. Berdasarkan Dobrovolsky (machine element) bahwa untuk beban statis angka keamanan : 1,25-2 ; beban dinamis : $2-3$; beban kejut $3-5$. Konstruksi rangka sepeda tersebut masuk dalam kelompok beban statis sehingga angka keamanannya minimal 1,25 maka untuk berat 9,32 $\mathrm{N}$ aman.

Uji performa kepresisian dilakukan tiga kali dengan kecepatan $50 \mathrm{rpm}$ dan temperature $210^{\circ} \mathrm{C}$ kemudian ke tiga produk hasil Printer 3D tersebut di bandingkan dimensinya dengan desain gambar 2D. Sehingga kita dapat mengetahui tingkat kepresisian produk hasil Printer 3D Tersebut, sebagai berikut:

Tabel 4. Hasil Pengukuran Benda Kerja

\begin{tabular}{lcccc}
\multirow{2}{*}{ NO } & DIMENSI & \multicolumn{4}{c}{ DIMENSI YANG DICAPAI } \\
& GAMBAR & Benda 1 & Benda 2 & Benda 3 \\
\hline 1. & $82 \mathrm{~mm}$ & $81,5 \mathrm{~mm}$ & $81,5 \mathrm{~mm}$ & $81,5 \mathrm{~mm}$ \\
2. & $42 \mathrm{~mm}$ & $41,5 \mathrm{~mm}$ & $41,5 \mathrm{~mm}$ & $41,5 \mathrm{~mm}$ \\
3. & $20 \mathrm{~mm}$ & $20 \mathrm{~mm}$ & $20 \mathrm{~mm}$ & $20 \mathrm{~mm}$ \\
4. & $15 \mathrm{~mm}$ & $15 \mathrm{~mm}$ & $15 \mathrm{~mm}$ & $15 \mathrm{~mm}$ \\
5. & $52 \mathrm{~mm}$ & $51,5 \mathrm{~mm}$ & $51,5 \mathrm{~mm}$ & $51,5 \mathrm{~mm}$ \\
6. & $67 \mathrm{~mm}$ & $66,5 \mathrm{~mm}$ & $66,5 \mathrm{~mm}$ & $66,5 \mathrm{~mm}$ \\
7. & $\varnothing 3 \mathrm{~mm}$ & $\varnothing 3 \mathrm{~mm}$ & $\varnothing 3 \mathrm{~mm}$ & $\varnothing 3 \mathrm{~mm}$ \\
8. & $\mathrm{R} 5$ & $\mathrm{R} 5$ & $\mathrm{R} 5$ & $\mathrm{R} 5$ \\
9. & $5 \mathrm{~mm}$ & $5 \mathrm{~mm}$ & $5 \mathrm{~mm}$ & $5 \mathrm{~mm}$ \\
10. & $42 \mathrm{~mm}$ & $42 \mathrm{~mm}$ & $42 \mathrm{~mm}$ & $42 \mathrm{~mm}$ \\
11. & $47 \mathrm{~mm}$ & $47 \mathrm{~mm}$ & $47 \mathrm{~mm}$ & $47 \mathrm{~mm}$ \\
12. & $42 \mathrm{~mm}$ & $42 \mathrm{~mm}$ & $42 \mathrm{~mm}$ & $42 \mathrm{~mm}$ \\
13. & $12 \mathrm{~mm}$ & $12 \mathrm{~mm}$ & $12 \mathrm{~mm}$ & $12 \mathrm{~mm}$ \\
\hline
\end{tabular}



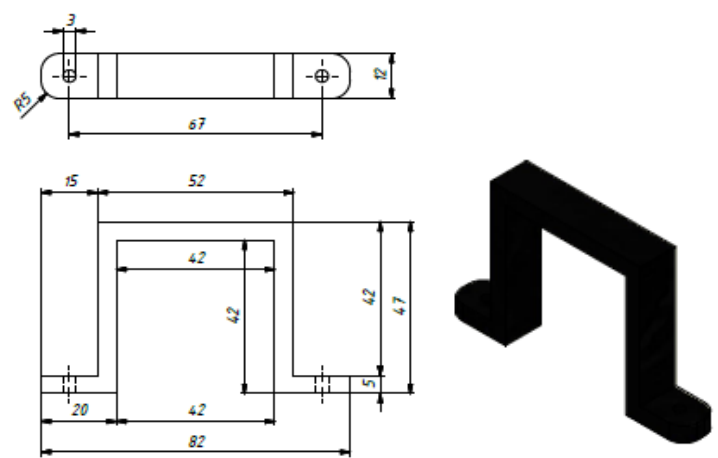

Gambar 7. Gambar kerja

\section{SIMPULAN}

Adanya perancangan 3D printer tipe Core $\mathrm{XY}$ dengan menggunakan software autodesk inventor 2015 dan telah dibuat sesuai dengan desain yang dirancang menghasilkan nilai kekuatan rangka yang cukup baik. Sementara produk hasil 3D printer tipe core XY memiliki kualitas yang baik karena memiliki ukuran yang presisi dengan desain 2 dimensi yang digambar.

\section{DAFTAR RUJUKAN}

Al-Maliki, Jabbar Qasim dan Alaa Jabbar Qasim Al-Maliki. 2015. The Processes and Technologies of 3D Printing. International Journal of Advances in
Computer Science and Technology. 4(10), 161-165.

Cleplak, dkk. 2014. 3D Printers - New Possibilities In Education. Advances In Science and Technology Research Journal. Vol. 8 (24): 96-101.

More, M. P. (2013). 3D Printing Making the Digital Real. International Journal of Engineering Science \& Research Technology, ISSN 2277-9655, 18221925.Hasan, M. Iqbal. 2002. Pokok Pokok Materi Metodologi Penelitian dan Apikasinya. Bogor: Ghalia, Indoesia.

Priyanto, S. A., dkk. 2005. Perancangan User Interface Printer 3D. Jurnal Mesin dan Industri. Vol. 2 (1): 35-45.

Sumantri, Dede. 2012. Peningkatan Kinerja Mesin Rapid Prototyping Berbasis Fused Desposition Modelling. Skripsi. Jakarta: Universitas Indonesia.

Sumbodo, W.dkk. 2008. Teknik Produksi Mesin Industri. Jakarta: Direktorat Pembinaan Sekolah Menengah Kejuruan.

Tseng, A.A. 2000. "Apparatus and methods for freeform fabrication of three dimensional object". US Patent No. 6030199. February 29. 